\title{
Über die Einwirkung der Reductionsmittel auf Cholsäure \\ von
}

\author{
Med. et Phil. Dr. Michael Seńkowski,
}

Assistinl.

Aus dem Laboratorium für medicinische Chemie in Krakau.

(Vorgelegt in der Sitzung am 7. Jänner 1898.)

In meiner früheren Mittheilung über die Cholsäure habe ich dieselbe als eine Orthophenylenverbindung charakterisirt, da sie durch weitgehende Oxydation mit Kaliumpermanganat in alkalischer Lösung Phtalsäure bildet. ${ }^{1}$ Als nächstes Ziel des weiteren Studiums über Cholsäure stellte ich mir die Bestimmung der beiden Seitenketten und dieses veranlasste mich, zuerst zu versuchen, die drei Hydroxylgruppen durch Reduction wegzuschaffen, um auf dieseWeise zu einer von Alkoholgruppen befreiten Carboxylsäure zu gelangen, deren weitere Bearbeitung schon wegen des vorausgesetzten grösseren Widerstandes gegen chemische Agentien mir leichter erschien.

In der mir zugänglichen Literatur habe ich nur zwei Arbeiten gefunden, die zu den wohlcharakterisirten Reductionsverbindungen führten; die eine von Mylius, der durch die Fäulniss der Galle oder reiner Cholsäuresalzlösung die um ein Sauerstoffatom ärmere Desoxycholsäure $\mathrm{C}_{24} \mathrm{H}_{40} \mathrm{O}_{4}$ erhielt ${ }^{2}$ und dessen Arbeit zur interessanten Polemik mit Latschinoff führte wegen der Behauptung des Letzteren, dass die Desoxycholsäure identisch mit der Choleünsäure sei. Dieser Streit ver-

1 Sitzungsber. der kais. Akad, der Wissenschaften in Wien, Bd. XCVII, Abth. JI, b.

2 Ber. der Deutchen chem. Ges. XIX, 369. 
anlasste Vahlen zum V'ersuche, die Desoxycholsäure durch rein chemische Reductionsmittel, nämlich durch Einwirkung von Zinkstaub auf die Eisessiglösung der Cholsäure zu erhalten, und wirklich gelang es demselben, die Desoxycholsäure in grösserer Quantität darzustellen. ${ }^{1}$ Da die Einwirkung des Zinkstaubes mir für meine Zwecke zu schwach erschien, griff ich zu einem stärkeren Reductionsmittel, namentlich zum Jodwasserstoff in Anwesenheit von rothem Phosphor.

$10 \mathrm{~g}$ der reinen, krystallisirten, durch längeres Erhitzen auf $110^{\circ}$ von Alkohol befreiten Cholsäure wurden im zugeschmolzenen Rohre oder sogar in einer Druckflasche mit der drei- bis vierfachen Menge rauchender Jodwasserstoffsäure und etwas mehr ais der theoretischen Menge rothen Phosphors 24 Stunden auf $100^{\circ}$ erhitzt. Die Säure schmolz zu einem durch Phosphor und Jod rothbraun gefärbten Kuchen, der sich leicht von der Jodwasserstoffsäure tremnen liess. Der Kuchen wurde pulverisirt, mit Wasser gut ausgewaschen, getrocknet, in heissem Eisessig gelöst, vom überschüssigen Phosphor abfiltrirt und in riel Wasser gegossen. Es entstand ein weisser, käsiger Niederschlag, der auf dem Filter gesammelt und mit Wasser gewaschen wurde. Das erhaltene Reductionsproduct erwies einen sauren Charakter, da es sich in verdünnter Kalilauge zu einer opalisirenden Flüssigkeit auflöste und sich aus der Lösung durch Salzsäure ausschied. Die mit Wasser bis zum Aufhören der Chlorreaction ausgewaschene Säure erwies sich aber jodhaltig und, da dieselbe amorph und durch kein Lösungsmittel zum Krystallisiren zu bringen war, konnte sie der Elementaranalyse nicht unterworfen werden. Um die Säure vom Jod zu befreien, wurde die rohe Eisessiglösung nach dem Abfiltriren von Phosphor mit Zinkstaub versetzt und einige Stunden im Wasserbade erhitzt. Die anfangs rothbraune Lösung entfärbte sich bald und nachdem diese vom überschüssigen Zinkstaub abfiltrirt und in viel Wasser gegossen wurde, fiel das reine, jodfreie Product als voluminöser, weisser, küsiger Niederschlag. Der Niederschlag wurde auf dem Filter mit Wasser tüchtig ausgewaschen, schliesslich in eine Schale gebracht und mit

1 Zeitschrift für phys. Chemie, XXIII, S. 09. 
ctwas Wasser enwärmt, wonach er sich zu einer gelblichen, spröden, harzähnlichen Nasse zusammenballte.

Die Elementaranalyse der lufttrockenen Substanz ergab:

In 100 Theilen:
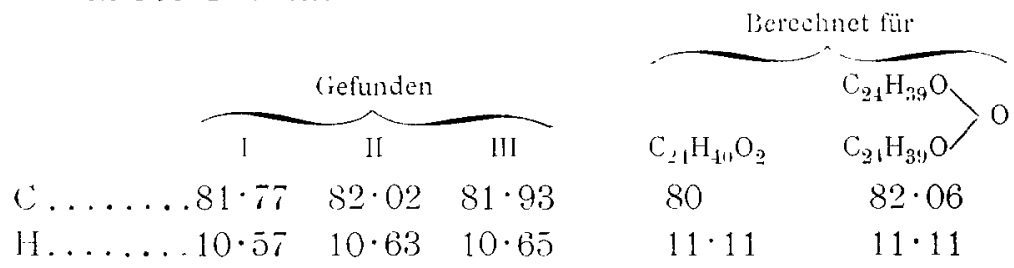

Die Differenzen, besonders im Wasserstoffgehalte, dürfen auf Verunreinigungen bezogen werden; übrigens zeigt die Elementaranalyse, dass wir es mit dem Anhydride der im freien Zustande nicht existirenden Monocarbonsäure $\mathrm{C}_{24} \mathrm{H}_{40} \mathrm{O}_{2}$, mit dem Anhydride der Cholylsäure, zu thun haben.

Die gelblich gefärbte, spröde, amorphe, harzähnliche Masse löst sich in Eisessig, Alkohol, sehr leicht in Äther und Petroläther; aus heiss gesättigter Lösung scheidet sie sich in Tropfen oder mikroskopischen Kügelchen ab; das Bemühen aber, sie zur Krystallisation zu bringen, blieb erfolglos. Der Schmelzpunkt der trockenen Masse liegt bei $75-80^{\circ}$.

Das Anhydrid löst sich leicht in verdünnten Laugen zu einer opalisirenden, schwer filtrirbaren, alkalisch reagirenden Flüssigkeit und aus dieser Lösung schied sich auf Zusatz von concentrirter Lauge das amorphe Kaliumsalz quantitativ aus. Dasselbe findet statt auch auf Zusatz von concentrirter Kochsalzlösung. Merkwürdig ist, dass cholylsaure Salze schon keinen bitteren Geschmack besitzen. Die Kaliumsalzlösung mit Baryumchlorid versetzt, ergab einen weissen, käsigen Niederschlag, der am Filter gewaschen, getrocknet und mit Alkohol oder Äther anhaltend extrahirt, freie Säure dem Lösungsmittel abgab. Die Blei-, Kupfer-, Silber-, Zink-und Calciumsalze rufen auch ähnliche Niederschläge hervor.

Behufs Esterificirung der Säure wurde das Anhydrid in absolutem Alkohol gelöst und die Lösung mit Chlorwasserstoff gesättigt. Nach einigen Stunden wurde das Gemisch in viel Wasser gegossen, das Ausgeschiedene in Äther gelöst, mit 
verdünnter Kalilauge und Wasser gewaschen und der Äther abdestillirt. Die zurückgebliebene rothbraune, klebrige Masse wahrscheinlich grösstentheils Äthylester der Säure - lud zur Elementaranalyse nicht ein.

Cholylsäureanhydrid mit äquivalenter Menge Bleisulphocyanats bei circa $250^{\circ}$ geschmolzen, ergab reichliche Mengen Kohlenoxysulphids unter gleichzeitiger Ausscheidung des Schwefelbleis. Nachdem die Gasentwicklung zu Ende war. wurde die erkaltete Schmelze mit Äther extrahirt und nach dem Abdampfen des letzteren wurde eine dunkel gefärbte amorphe Masse erhalten, die schon dem Ansehen nach stark verunreinigt schien. Dieselbe war unlöslich in kalter Kalilauge, aber mit alkoholischer Kalilösung gekocht, bildete sie Cholylsäure zurück unter gleichzeitiger Ausscheidung von Ammoniak.

Die Versuche, das unreine Nitril zu reinigen, oder durch Reduction in ein Amin zu überführen, blieben erfolglos: Die Reduction mit Natrium in Alkohollösung, mit Zinkstaub in Eisessig, mit Zinn und Salzsäure in Alkohollösung ergaben kein basisches Product.

Brom wirkt auf Cholylsäureanhydrid, in Schwefelkohlenstoff gelöst, sehr langsam unter Entwickelung von Bromwasserstoff, rascher im directen Sonnenlichte. Concentrirte Salpetersäure mit Schwefelsäure bilden ein nicht näher untersuchtes Nitroproduct. Die Nitro- und Bromsubstitutionsverbindungen beabsichtige ich in der nächsten Abhandlung zu beschreiben. 